Editorial

\title{
A New Beginning
}

\author{
Shyamkumar N. Keshava ${ }^{1}$ Sanjeeva P. Kalva² \\ ${ }^{1}$ Department of Radiology, Christian Medical College, Vellore, Tamil \\ Nadu, India \\ 2 Division of Interventional Radiology, Department of Radiology, \\ University of Texas Southwestern Medical Center, Dallas, TX, USA \\ J Clin Interv Radiol ISVIR 2017;1:1-2.
}

We strongly believe that a new journal dedicated to the clinical practice of Interventional Radiology (IR) will have a positive impact on the growth of IR both in India and abroad. Journal of Clinical Interventional Radiology (JCIR) is an initiative from India with a global presence.

An official mandate to start a new IR journal was given in February 2016 during the annual conference of the Indian Society of Vascular and Interventional Radiology (ISVIR) at Bangalore. There were suggestions regarding several aspects of the journal, including the name, theme, content, appearance, scope, frequency, publisher, and so on. The office bearers of the ISVIR and the editorial members of JCIR are thankful to all the experts and well-wishers from different corners of the world who guided our initial efforts and continue to support this initiative. In a short evolutionary phase, our team has extensively used electronic media for many discussions.

With the birth of JCIR, sure, we are excited! At the same time, we are also well aware of the other side of the coin-the need to plan for a healthy growth of the journal. The first issue was made possible by many authors submitting manuscripts within the required time, knowing well that every manuscript was going to be peer-reviewed. The editorial team, reviewers, and publishers have taken it as a challenge to publish the first issue during the year 2016.

Address for correspondence Shyamkumar N. Keshava, DMRD, DNB, FRCR, FRANZCR, Department of Radiology, Christian Medical College, Ida Scudder Road, Vellore 632004, Tamil Nadu, India (e-mail: aparna_shyam@cmcvellore. ac.in).
JCIR is a peer-reviewed, open access, online and print journal that supports the science and practice of IR worldwide. The aim of this journal is to enhance the knowledge of medical practitioners in the field of IR. It aims to give priority to the dissemination of original research work in the field of IR that can potentially impact patient care and outcomes. It also seeks to bring to the readers reviews of standard interventional radiological procedures, clinical practice guidelines, brief reports, and insightful debates in the subject area. The journal will be published three times a year, in April, August, and December.

JCIR is committed to maintaining the best ethical practices of scientific publication while remaining mindful of social and environmental concerns. It strives to provide the scholarly experience to authors and readers alike. We are committed to a high standard while delivering the updated knowledge in the field of IR. Our editorial and reviewers' team has been planned in such a way that there is the shortest possible reviewing time. We are proud to be partners with an efficient reputed publisher, Thieme. We wish to remain "environment-friendly" with a limited number of hard copy prints. Needless to say that our aim is to get JCIR indexed at the earliest. We thank you all for your encouragement and support. We look forward to getting similar support in the future.
DOI https://doi.org/

10.1055/s-0036-1597955. ISSN $0000-0000$.
Copyright $\odot 2017$ by Indian Society of Vascular and Interventional Radiology 